\title{
Sleep Disorders and Headache: A Review of Correlation and Mutual Influence
}

Elena A. Korabelnikova • Alexey B. Danilov • Andrey B. Danilov •

Yulia D. Vorobyeva · Nina V. Latysheva · Ada R. Artemenko

Received: April 15, 2020 / Published online: July 3, 2020

(C) The Author(s) 2020

\section{ABSTRACT}

The review is devoted to the complex relationship between headache and sleep disorders. The shared neuroanatomical structures of the nervous system involved in pain perception and sleep are shown, and mechanisms of comorbidity between headaches and sleep disorders are considered. Various types of headaches in the continuum of the sleep-wake cycle are described. Both pharmacological and nonpharmacological approaches to treatment are examined in detail, with the biochemical basis of the drug action.

Keywords: Headaches; Non-pharmacological management; Pharmacotherapy; Sleep; Sleep disorders

Digital Features To view digital features for this article go to https://doi.org/10.6084/m9.figshare.12446018.

E. A. Korabelnikova ( $\square)$ · A. B. Danilov ·

A. B. Danilov · Y. D. Vorobyeva · N. V. Latysheva .

A. R. Artemenko

Department of Neurology, Institute for Postgraduate

Education, Sechenov First Moscow State Medical

University (Sechenov University), Moscow, Russia

e-mail: e_korabel@mail.ru

\section{Key Summary Points}

The review presents data on comorbidity of headaches and sleep disorders.

Pathophysiological and psychological mechanisms of their mutual influence are considered.

The article focuses on the comorbidity of various types of headaches and sleep disorders.

The pharmacological and nonpharmacological approaches to treatment are considered, taking into account the specifics of the interaction between cephalgia and sleep disorders and the characteristics of drug action.

\section{INTRODUCTION}

Sleep is an integral part of our life and one of the basic needs of a person, and its disorders are a significant clinical problem. Almost $50 \%$ of the population suffer from various types of sleep disorders. Sleep medicine studies various pathological phenomena of the sleep-wake cycle. Headaches are one of the most common medical problems (affecting $50-75 \%$ of the adult population according to the World Health 
Organization). In this regard, both phenomena have acquired the status of a global health burden. In the third revision of the International Classification of Headache Disorders (ICHD-3, 2018), sleep is mentioned 38 times [1], and headache in turn is listed in the International Classification of Sleep Disorders (ICSD) among the symptoms of sleep disorders [2]. The American Academy of Sleep Medicine considers headache associated with sleep one of the most common complaints of patients with headaches (migraines or other types) [3].

The relationship between headache and sleep disorders is complex and multidimensional. In a patient suffering from both a sleep disorder and a headache disorder it is difficult to establish causal relationships, which are usually bidirectional. Comorbidity of these two syndromes leads to their chronification and increases the burden, causing worsening of both disorders, decreasing the quality of life, increasing the frequency of complications, and reducing treatment effectiveness. The purpose of the review is to consider various aspects of the relationship between headache and sleep disorders, the mechanisms of their comorbidity, and to analyze the possibilities of therapy for these syndromes, taking into account their interaction. This article is based on previously conducted studies and does not contain any studies with human participants or animals performed by any of the authors.

\section{HISTORICAL OVERVIEW}

The close and complex relationship between sleep and headache has been troubling many clinicians for centuries. The earliest publications that mention a connection between headache and sleep include the following: Romberg's indication that "an attack (migraine) usually ends in a deep and refreshing sleep" in 1853 [4]; Leveing's reference to the relationship between migraine attacks and sleep in the manuscript "The effect of sleep on headache relief" in 1873 [5]; Freud's concept of sleep headache and its psychodynamic interpretation (1926) [6]; Bing's mention (1945) of headaches that occur when awakening from sleep [7]; Gans' (1951) data on the reduction of migraine attacks after selective sleep deprivation, especially of deep sleep [8]; and discovery of the connection between nighttime headache and sleep stages by Dexter and Weitzman [9]. One of the first works aimed at a systematic multidimensional analysis of the relationship between headache and sleep was performed in 1990 by Sahota and Dexter [10]. Later, Sahota and Dodik [11] emphasized the link between sleep and headache in the ICSD 2nd edition, a 2005 diagnostic and coding guide. In 2014, the first large-scale epidemiological study was conducted in Denmark, which assessed the frequency of headache and comorbid sleep disorders [12]. According to the study, 18.1\% of people reported having a headache and insomnia at the same time, $16.3 \%$ suffered only from headaches, and $21.1 \%$ had only problems with sleep. Comorbid pathology was more often observed in women and middle-aged people. Low socioeconomic status, unhealthy lifestyle (overweight/obesity), high levels of stress, anxiety, and depression were also identified as risk factors. The authors concluded that there is a high degree of comorbidity of headaches and sleep disorders, warranting timely diagnosis, treatment, and prevention. It also emphasizes the importance of preventive measures, including lifestyle changes, reducing the impact of stress, and screening for depression and anxiety, which can be of great importance for the treatment and prevention of comorbid headaches and sleep disorders $[3,12]$.

\section{NEUROBIOLOGICAL AND PSYCHOLOGICAL MECHANISMS OF COMORBIDITY BETWEEN HEADACHES AND SLEEP DISORDERS}

\section{Sleep and Pain Perception}

The transition from wakefulness to sleep is accompanied by development of certain deafferentation-an increase in response to sound, tactile, and proprioceptive stimuli [13, 14]. It has been shown that this modulation occurs in the thalamus. Having said that, thalamocortical 
neurons that transfer sensory information to the appropriate somatotopical areas show a decrease in firing frequency with the transition to burst mode, which apparently allows the limiting of the amount of information and increasing the threshold of awakening to afferent stimuli [15]. It is assumed that the modification of afferent information is also carried out at the brainstem and spinal levels: sensitive trigeminal nuclei, solitary tract nucleus, and posterior horns of the spinal cord. This is confirmed by the evaluation of nociceptive flexor reflex (NFR) components during transition from wakefulness to sleep [16]. Studies conducted on healthy volunteers have shown a decrease in pain thresholds when sleep time is reduced [17], and a decrease in pain sensitivity when sleep time is increased [18]. Similar results were demonstrated in animal experiments [19].

Many of the structures, pathways, and neurotransmitters involved in sleep disorders are also part of the headache pathophysiology. The convergence between sleep and headache pathways is primarily localized in the diencephalic and brainstem structures of the brain (Fig. 1).

The key structure linking headache and sleep is the hypothalamus, which is a relay station for all types of sensation and at the same time a circadian pacemaker. Studying the pathophysiology and function of the hypothalamus simultaneously in headache and sleep disorders may explain the relationship between pain perception involving trigeminal nerve and sleep induction. The trigemino-cervical complex plays an important role in the generation of headache and is connected to a number of brainstem structures. Nociceptive information enters thalamic nuclei and its activation plays a role of great importance in the development of migraine and cluster headache. The trigeminal nerve sends afferent impulses to the intra- and extracranial structures and blood vessels, the spinal trigemino-cervical complex [21].

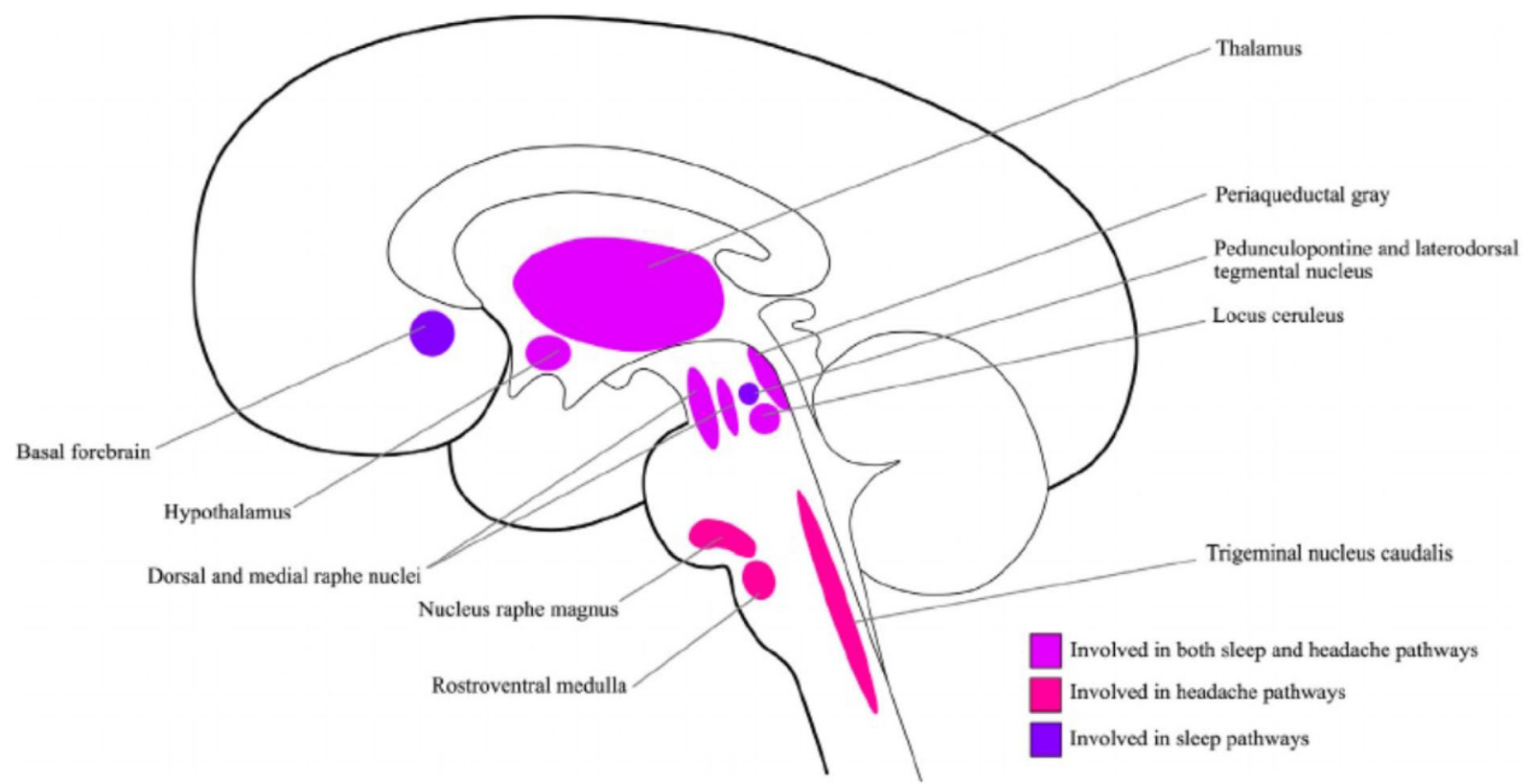

Fig. 1 Key structures involved in the pathophysiology of sleep disorders and headache. 1. Structures involved in the pathophysiology of both pain and sleep disorders: thalamus, hypothalamus, locus coeruleus, periaqueductal gray matter. 2. Structures involved in the pathophysiology of pain: nuclei raphe magnus, rostroventral medulla oblongata, trigeminal nucleus caudalis. 3. Structures involved in the pathophysiology of sleep disorders: pedunculopontine and laterodorsal tegmental nucleus, basal forebrain Reprinted from Sleep and Neurologic Disease, O'Hare, M. and Cowan, R.P., Sleep and Headache, pages 201-225, Copyright 2017, with permission from Elsevier [20] 
During transition to sleep the orexinergic system activates the ventrolateral preoptic nucleus. Direct inhibition of this system and reduction of orexinergic support of sleep determine rapid transitions from sleep to wakefulness and vice versa. The orexinergic system, including neuropeptides (orexin A and B), is represented in the posterior, lateral, and paraventricular hypothalamus [22]. Orexin receptors are located in the prefrontal cortex, thalamus, and subcortical areas, and are involved not only in ensuring wakefulness but also in pain sensitivity modulation, thermoregulation, and neuroendocrine and autonomic functions [23]. These areas are also involved in the nociceptive modulation of the trigemino-vascular complex [24]. Disturbance of the activity of sleep centers in the anterior hypothalamus causes instability of the thalamic "relay station", while the natural sleep blockade of the sensation pathways is not so effective, and pain threshold is reduced $[25,26]$.

Other structures involved in these two pathophysiological processes include the locus coeruleus, the ventral part of the periaqueductal gray matter, and the dorsal raphe nucleus. These cell structures send monoaminergic projections to the thalamic nuclei, lateral hypothalamus, basal forebrain, and cortex. They are important in maintaining arousal and are very active during waking hours [26, 27]. In addition, the ventrolateral part of the periaqueductal gray matter plays a specific role in suppressing REM sleep (i.e., it is a REM sleep zone) and is innervated by the orexinergic neurons of the lateral hypothalamus [21]. In addition to their role in arousal, these brainstem structures also play an important role in modulating headache perception, acting as an endogenous "antinociceptive system" [28].

Speaking about the neurochemistry of the headache-sleep disorders link, the important role of orexin and melatonin cannot be underestimated.

Orexin/hypocretin is an excitatory neuropeptide hormone that promotes wakefulness and suppresses rapid sleep [21]. Orexin/ hypocretin deficiency is observed in narcolepsy. At the same time, up to $80 \%$ of patients with narcolepsy complain of headaches, among which tension-type headaches and migraine are especially common [29]. Studies show that orexin/hypocretin is involved in pain modulation, including the caudal nucleus of the trigeminal nerve. Polymorphism of the orexin/ hypocretin 2 receptor gene is associated with cluster headache [30].

Melatonin is a neurohormone produced primarily by the pineal gland and regulated by the suprachiasmatic nucleus. Melatonin plays a crucial role in regulating circadian rhythms, including initiating sleep and maintaining its rhythms. The melatonin secretion has a diurnal rhythm-it increases in the dark and is suppressed in the presence of light; the process is regulated by the suprachiasmatic nuclei of the hypothalamus. At the same time, melatonin can have an analgesic effect, and disturbance in melatonin secretion can lead to headaches. Mechanisms underlying the interaction between melatonin and headache may include potentiation of the GABAergic inhibition of pain pathways, modulation of 5-HT signaling, reduction of proinflammatory cytokine production, inhibition of nitric oxide synthesis, antioxidant effects, and induction of cytokines acting on opioid receptors (melatonin-induced opioids) [28, 31]. In patients with chronic migraine and comorbid insomnia, a significant decrease in melatonin levels was observed in addition to the delayed sleep phase syndrome [32].

There are data showing delayed and decreased melatonin secretion in patients with cluster headache and menstrual migraine, as well as a high prevalence of non-specific headaches in patients with narcolepsy [33]. Reduction of melatonin secretion is proposed to be considered as a pathophysiological explanation of the fact that hypnic headache is a disease of middle-aged and elderly patients $[26,28]$.

Another neurotransmitter that plays a role in the pathophysiology of both headache and sleep disorders is adenosine, which acts on the $A_{1}$ and $A_{2 A}$ receptors in the central nervous system. Stimulation of $A_{1}$ receptors has an antinociceptive effect. Stimulation of $\mathrm{A}_{2 \mathrm{~A}}$ receptors causes pain. Sleep-stimulating effects of adenosine are mainly mediated by activation of the $A_{1}$ receptor, with some contribution of 
$\mathrm{A}_{2 \mathrm{~A}}$ receptor activation [34]. Administration of adenosine may cause migraine in susceptible patients [27]. However, increased circulating levels of adenosine were recorded during migraine attacks [35].

Abnormal serotonin signals in the brainstem can also link headache and sleep. The main serotoninergic nucleus of the central nervous system is the dorsal raphe nucleus. This is a key antinociceptive structure [36], which is also involved in stimulating wakefulness. However, an important role of serotonin in the pathophysiology of migraine has long been assumed $[37,38]$.

\section{Psychological Factors}

The bidirectional relationship between headache and sleep disorders is mediated not only by biological factors but also by psychological factors. First, they are linked by a common emotional and personal background: anxiety, vulnerability to stress, low self-esteem, and maladaptive behaviors in relation to the disease.

According to the results of a recent Danish cross-sectional population study [12], presence of headache and comorbid sleep disorders significantly increased the level of anxiety and depression and worsened the quality of life. Engstrom et al. showed that increase in anxiety was associated with more superficial sleep in both patients with migraine and healthy individuals, but significantly more so in patients with migraine [39].

Figure 2 presents a bio-behavioral model of the link between chronic insomnia and chronic headache [40]:

- Attempts to overcome headaches can accelerate and increase sleep disorders.

- Disruption of sleep physiology increases the tendency of having a headache.

- With time, these cycles interact and lead to transformation or chronification of the preexisting headache.

Chronic headache can be considered as a predisposing factor for sleep disorders, because it encourages the use of maladaptive strategies, such as increasing daytime sleep, spending more time in the bedroom during wakefulness and pain, and taking sleeping pills before going to bed and stimulating drinks during daytime [41, 42].

Pain further worsens sleep, becoming a source of stress and creating a vicious circle [41]. Sleep disorders have been shown to change the

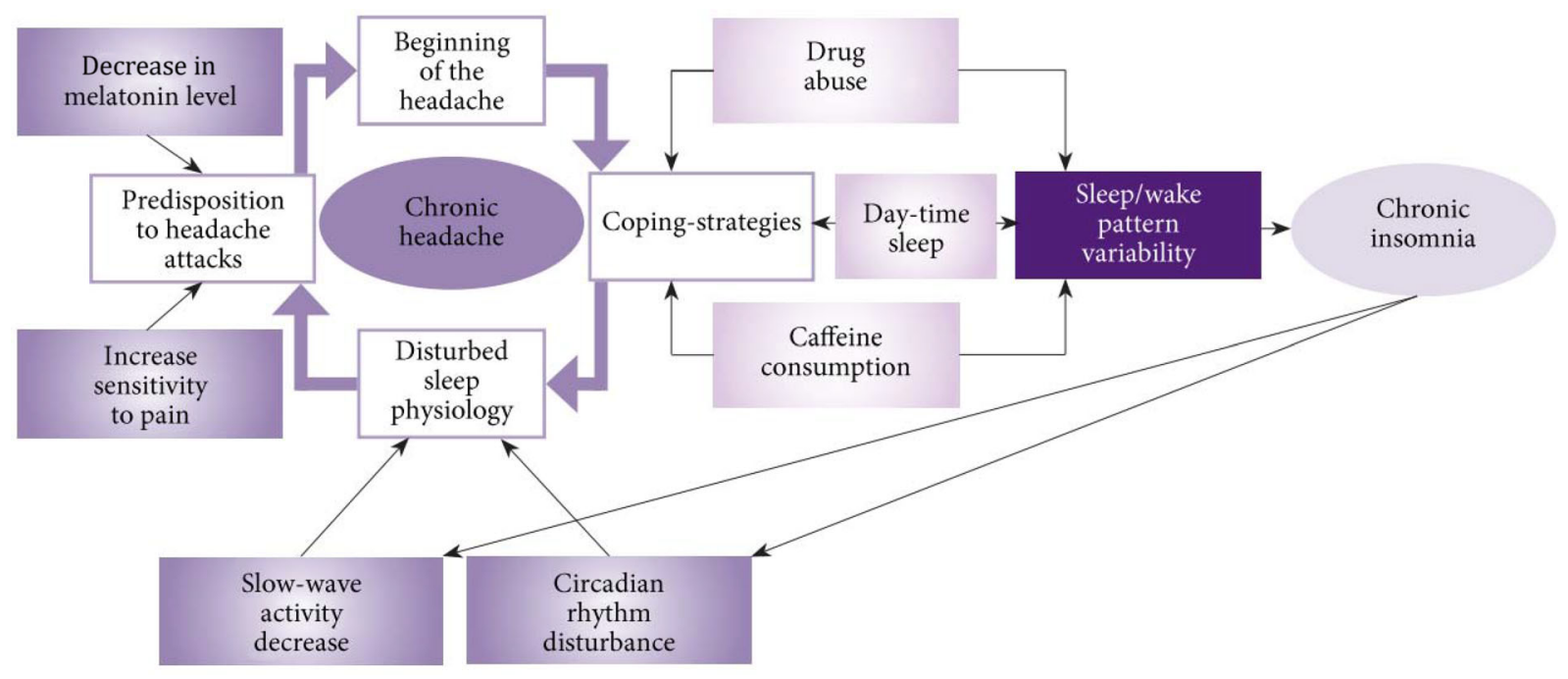

Fig. 2 Bio-behavioral model of the link between chronic insomnia and chronic headache Reproduced with permission from Koreshkina MI. Relationships of Sleep Disorders and Headache. Zh Nevrol Psikhiatr Im S S Korsakova.
Special edition "Sleep and sleep disturbance -6 ". 2018;35:72-79 
patient's attitude to their headache leading to dramatization and catastrophization [43]. Both the sleep disorder and chronic pain significantly increase the risk of depression and anxiety that further affects the complex relationship between sleep and headache.

\section{BIDIRECTIONAL RELATIONSHIP BETWEEN HEADACHE AND SLEEP DISORDERS}

Sleep disorder and pain are often comorbid and lead to serious negative effects on health and quality of life. In this case, both conditions undoubtedly have bidirectional relationships. Many studies have shown a positive correlation between chronic pain intensity and degree of sleep disturbance [43]. In addition, it was shown that the structure of sleep disorders in patients with chronic pain is similar to the profile in patients with primary insomnia [44].

Data from various authors show a high frequency of comorbidity of different variants of cephalgia with different variants of sleep disorders [20]:

1. Migraine can be associated with insomnia $[45,46]$, parasomnia (night terrors, somnambulism), restless leg syndrome, and bruxism [47].

2. The most frequent sleep disorder accompanying cluster headache is central and obstructive sleep apnea [48, 49].

3. Night awakenings (associated with sleep disorders by definition) [1] are often observed in patients with hypnic headache.

4. Tension headache is often accompanied by insomnia $[50,51]$.

5. Insomnia [46, 52] and obstructive sleep apnea syndrome with snoring [53, 54] can often be seen in patients with chronic daily headache.

Various mechanisms of comorbidity between headaches and sleep disorders can be proposed. First, both phenomena can develop on the common ground of systemic pathology (anemia, hypoxemia), be independently comorbid to a number of metabolic disorders, such as obesity, type 2 diabetes, or have common causes and provoking factors (emotional stress, anxiety, and depressive disorders). Second, both conditions can affect each other. Opinion on the predominant degree of influence in the combination of pain and sleep varies. Some researchers think that sleep disorders increase headache risk more significantly than vice versa. A typical example is hypnic headache [25]. Patients with insomnia have been shown to have a 2-3-fold increased risk of migraine and tension-type headache $[51,55,56]$, as well as chronic daily headache [52].

Others believe that pain affects sleep more than sleep affects pain $[57,58]$. According to Finan, sleep disorders were registered in $67-88 \%$ of patients with chronic pain; while only $50 \%$ of patients with insomnia complained of pain [45]. The severity of sleep disorders was shown to correlate with increased headache frequency [50]. However, it has been shown that pain stimuli alone do not explain sleep disorders to the extent reported by patients with headache, since in healthy people painful stimuli during sleep only lead to short-term cortical arousal and postural adjustments without significant sleep disturbance or memory of a nightmare the next day. Chronic pain is associated with increased activity of systems that modulate ascending activation and nociception, and also violates the microarchitectonics of sleep $[41,59,60]$. Another important aspect is the impact of headache medications on sleep [61].

Sleep in relation to headache acts as a reliever, provocative factor, and modifier of the pain syndrome (Table 1 ).

The most striking example of the headacherelieving function of sleep: the attack stops if the patient manages to fall asleep. However, there is a special form of migraine-"weekend migraine", when a headache occurs after waking up as a result of excess sleep. Lack of night sleep and dissatisfaction with sleep quality often lead to morning headaches.

The provocative role of sleep is clearly visible in patients with cluster headaches, while sleep deprivation plays a relieving role: a single night of sleep deprivation led to the absence of cluster attacks for 4 days. With these symptoms shortterm sleep deprivation is indicated, leading to 


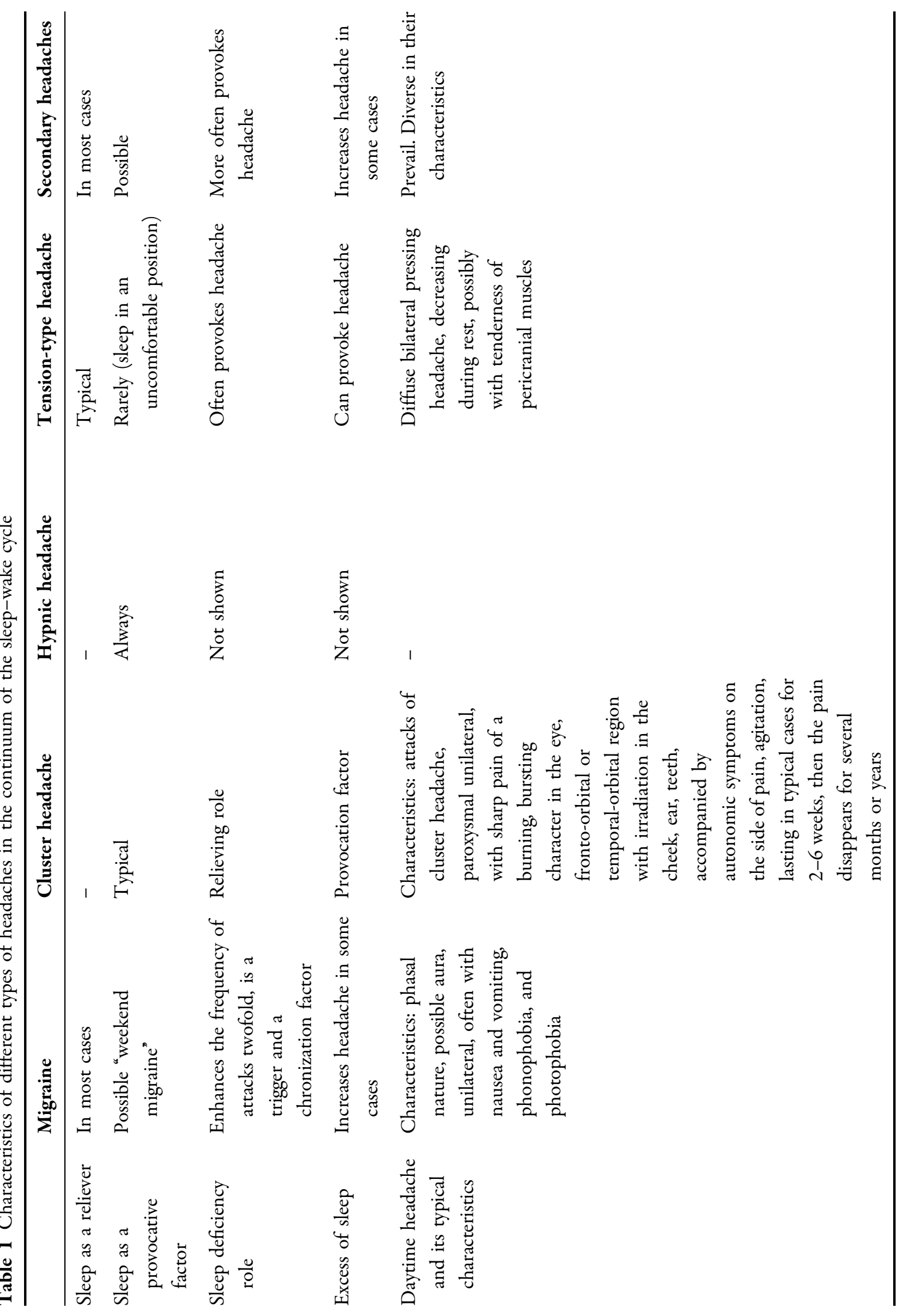




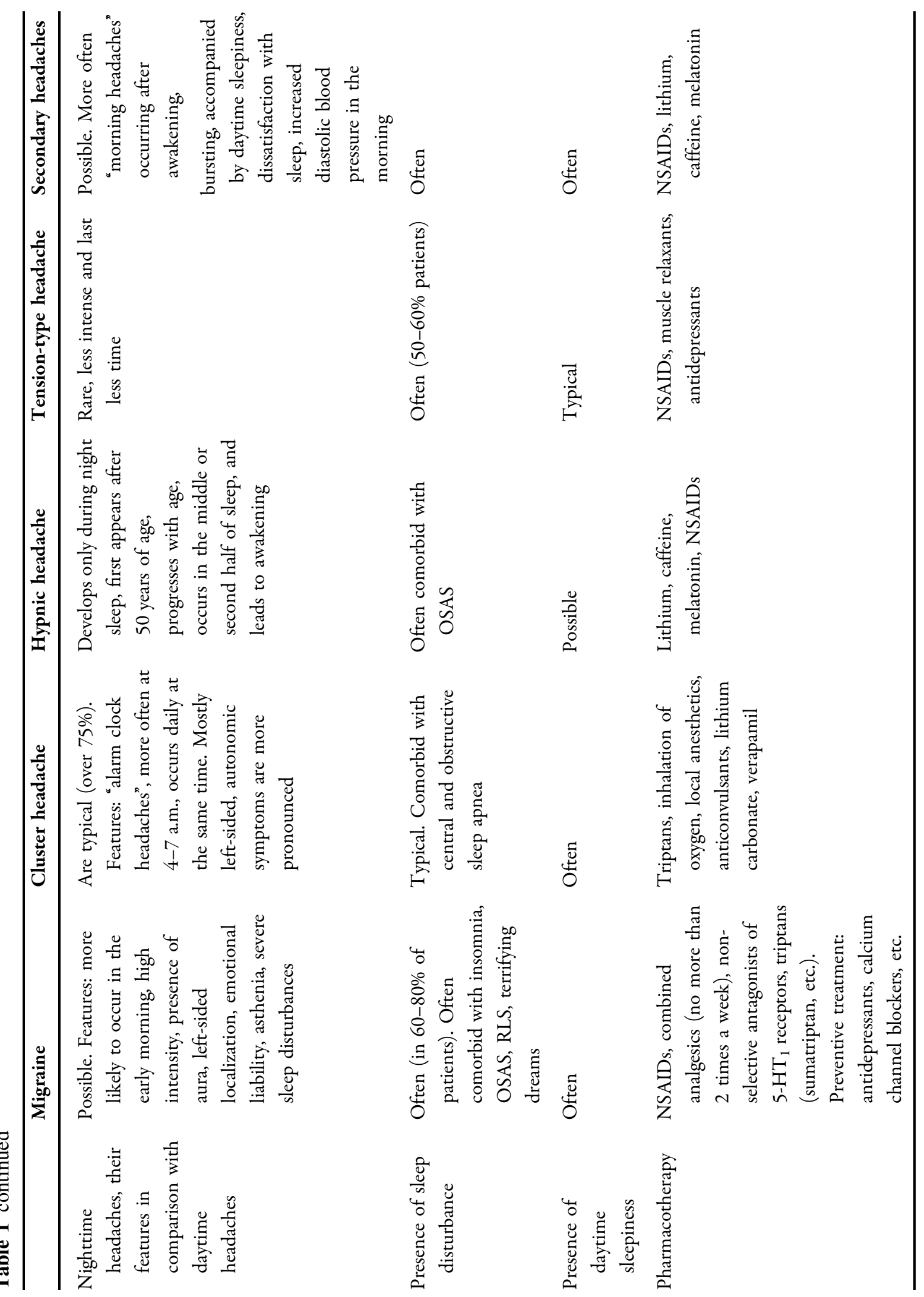




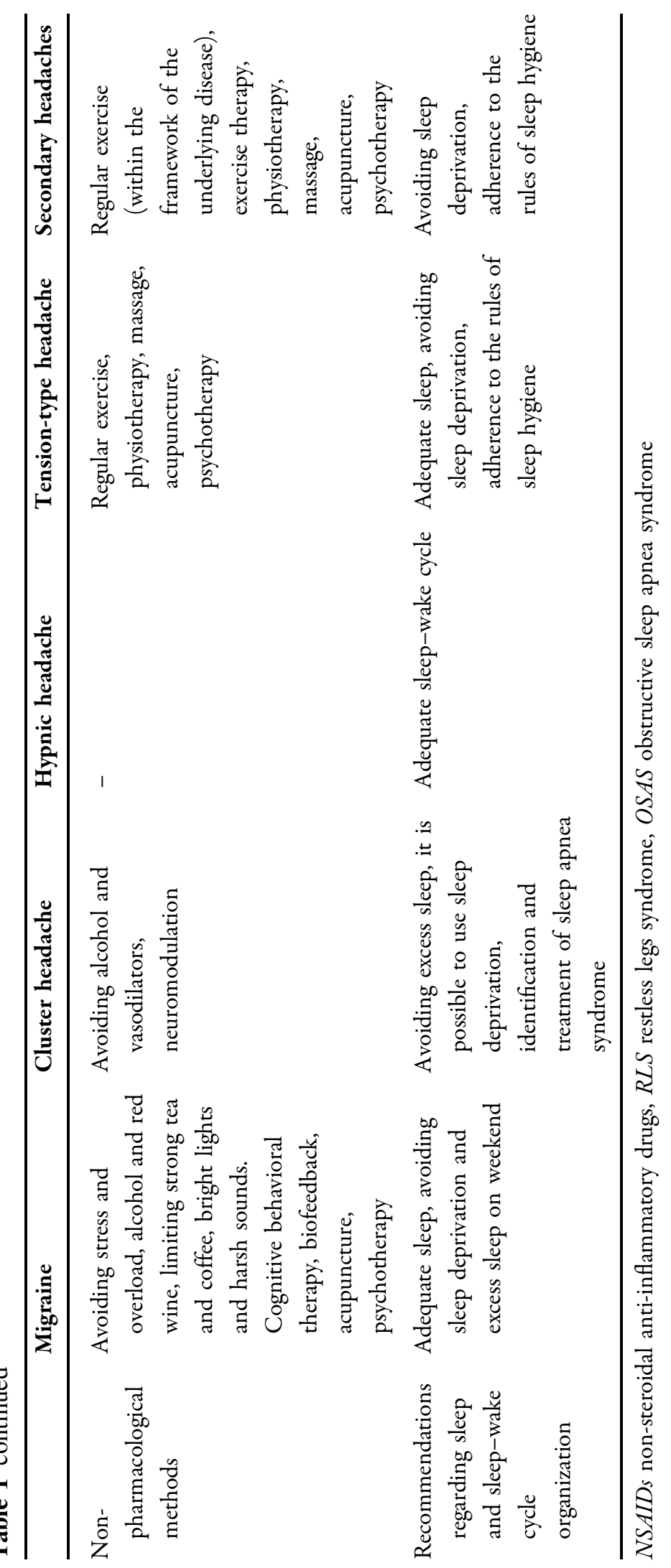


an improvement and absence of pain for about 5 days.

There is also a form of headache that occurs only in sleep-hypnic headache [25], which accounts for $0.07-0.35 \%$ of all forms of headache observed in specialized clinics. It develops after the age of 50 and progresses with advancing age. Most patients report a single episode of headache occurring in the middle or second half of sleep (from 2 to 4 a.m.) at the same time that wakes them from sleep.

Various types of sleep-related headaches have been described: headaches occurring during sleep [7], after sleep [62, 63], and at various stages of sleep [25, 64]. Some types of sleep-related headaches (hypnic headache) are directly related to sleep, while others (cluster headache) occur through common neurobiological mechanisms.

During a headache, patients often see dreams of dramatic and intimidating nature [65], but without scenes of their own death. However, such dreams do not serve as triggers for migraine attacks. As a rule, headache attacks interrupt sleep only at the time of the attack, but do not deprive the patient of sleep for the whole night; therefore, complaints from patients with headache about a complete lack of sleep are a definite sign of the presence of other diseases (anxiety and depression), which cause sleep disturbance.

Sleep disorders, sleep apnea for example, can also lead to secondary headaches and, in turn, affect the manifestation of the primary headache.

Therefore, such comorbid conditions as headaches and sleep disorders may increase their common burden and chances of chronification.

\section{TREATMENT}

The relationship between headaches and sleep disorders should be considered when choosing therapeutic options for this patient cohort.

Firstly, lifestyle recommendations should be provided on the basis of the form of the headache. In some forms of cephalgia sleep deprivation is a pain provocation factor (migraine, tension-type headache), while in other forms an excess of sleep is a pain provocation factor (cluster headache).

Secondly, when prescribing treatment for patients with comorbid headache and sleep disorders, one should be guided by the nature of their mutual influence. In particular, the importance of sleep improvement, and, conversely, the importance of relieving pain for sleep improvement cannot be underestimated. Therefore, the therapeutic program for such patients should be comprehensive, taking into account the mutual influence of these syndromes in a particular patient, as well as the influence of each recommended treatment method on comorbid syndromes (Table 1).

The foregoing relates, first of all, to pharmacotherapy. In this regard, priority is given to drugs that positively affect sleep and at the same time have an analgesic effect. These include, in particular, melatonin medications. Given the effects of circadian rhythm normalization and sleep duration improvement, melatonin can be used in patients with various types of headaches (migraine, cluster headache, hypnic headache) as add-on therapy. The use of melatonin for 3 months in patients with sleep disorders and comorbid headache reduced the intensity and frequency of headache attacks [66]. Decrease in pain severity in patients with migraine taking melatonin has also been shown [67]. A pilot study of adult patients suffering from migraine and tension-type headache showed that a 6-month treatment with melatonin resulted in decreased headache frequency and improved quality of life [68].

The special role of serotonin and adenosine in the pathophysiology of both headache and sleep disorders opens up additional prospects for the use of drugs that affect their metabolism. In particular, given the relationship between adenosine, sleep, and nociception, the use of both adenosine agonists and antagonists in primary headaches has been investigated [69].

The analgesic effect of antidepressants has long been known. It is believed to be associated with increased activity of noradrenergic and serotonergic pathways, which inhibit transmission of nociceptive impulses in the central nervous system. Tricyclic antidepressants have a 
more pronounced analgesic effect, while selective serotonin reuptake inhibitors (SSRIs) have fewer side effects. Selective serotonin and norepinephrine reuptake inhibitors (SSNRIs) have a longer analgesic effect than those affecting only one of the aminergic systems $[70,71]$.

At the same time, antidepressants have been proven to exert a positive effect on sleep and also have a psychomodulating effect, which is especially important given the special role of anxiety-depressive disorders in the etiopathogenesis of headaches and sleep disorders [72].

Medications used for preventive treatment of headaches of sleep and wakefulness are identical; however, the time of their intake should be optimized. In order to prevent nighttime headaches, drug intake in the afternoon is recommended with slow dose titration.

Particular attention should be paid to the pain medications, the pharmacokinetics of which allows them to be effectively used to stop night attacks, in particular, extended release analgesics. Such drugs include, in particular, the non-steroidal anti-inflammatory drug ibuprofen SR (sustained release). The analgesic effect of the drug is due to the blockade of cyclooxygenase (COX) 1 and COX2 and an inhibitory effect on the synthesis of prostaglandins. As a result of the prolonged absorption phase, plasma concentrations of ibuprofen are maintained longer in the systemic circulation, which helps to preserve the analgesic effect of the drug throughout the entire night's sleep. Clinical trials showed a significant relief in night pain and improvement of night sleep quality with ibuprofen SR [73, 74].

At the same time, a number of drugs that are effective in treating one comorbid condition can negatively affect another. These include, in particular, beta-blockers, one of the first-line prophylactic medications for frequent migraine attacks, that cause disturbing dreams and frequent night awakenings. They reduce endogenous melatonin secretion, which leads to suppression of sleep signal and can cause sleep disturbances and its fragmentation. Tricyclic antidepressants (amitriptyline), used in the treatment of frequent migraine attacks, not only reduce the total duration of sleep but also increase morning and daytime sleepiness, and often provoke nightmares. Triptans used as acute treatments for migraine can cause drowsiness, which apparently is the result of their direct effect on the serotonergic system. Benzodiazepines prescribed for sleep disorders can not only exacerbate existing headaches but also cause them. Medication overuse headache worsens if drugs that act on the central nervous system are prescribed [61].

Along with pharmacological treatment there are other methods aimed at reducing the frequency and severity of pain and normalizing sleep.

In particular, a positive effect of sleep hygiene has been shown in patients with migraine [75]. This method implied adherence to the following basic rules:

- Planning sleep time

- Excluding television watching, reading, or music in bed

- Use of the visualization method (imagine a pleasant situation and images)

- Restriction of food and fluid intake at bedtime

- Excluding daytime sleep

The effect of sleep hygiene on the frequency of migraine attacks (a threefold decrease) in preschool and school children has also been shown [76].

The positive role of instructing patients with headaches on lifestyle-related issues, adhering to a clear sleep-wake schedule (Table 1), and the need to reduce alcohol and stimulating drinks [77] has been shown.

Among effective methods in the complex therapy of these two comorbid syndromes, the vital role of psychotherapy needs to be underlined. Its efficacy has been confirmed by numerous studies of patients with different types of headaches and sleep disorders [78]. Psychotherapy is considered the mainstream treatment for insomnia and is effective in headache disorders, in particular, migraines, tension-type headaches, and chronic pain. Cognitive behavioral psychotherapy involves the use of specific techniques aimed at changing behavior associated with sleep/headache (behavioral therapy) and ideas about one's 
sleep/headache (cognitive therapy), since the techniques used in both cases are aimed, in fact, at the same targets (decrease muscle tension and stress level, identify dysfunctional beliefs about a problem, and eliminate catastrophization, etc.). This treatment method has a high level of evidence, confirmed by numerous studies and meta-analyses.

Other non-drug methods of treatment include acupuncture, phototherapy, massage, and physical activity.

\section{CONCLUSION}

Sleep disorders and headache cause and/or exacerbate each other in a complex, bidirectional manner, which is largely determined by the shared neurobiological substrate and is also mediated by emotional and personality disorders. Common causes and comorbid diseases (in particular, anxiety and depression) further modify and complicate this relationship, leading to a decrease in the quality of life. This dictates the need to diagnose and take into account comorbidity between headaches and sleep disorders in clinical practice and management of this category of patients. Development of new pharmacological strategies that target specific receptors can provide a new understanding of the mechanisms of sleep regulation and the relationship between sleep and wake systems and headache-generating systems.

\section{ACKNOWLEDGEMENTS}

Funding. No funding or sponsorship was received for this study or publication of this article.

Authorship. All named authors meet the International Committee of Medical Journal Editors (ICMJE) criteria for authorship for this article, take responsibility for the integrity of the work as a whole, and have given their approval for this version to be published.
Disclosures. Elena Korabelnikova, Yulia Vorobyeva, Nina Latysheva and Ada Artemenko have nothing to disclose. Alexey Danilov and Andrey Danilov are members of the journal's Editorial Board.

Compliance with Ethics Guidelines. This article is based on previously conducted studies and does not contain any studies with human participants or animals performed by any of the authors.

Data Availability. Data sharing is not applicable to this article as no datasets were generated or analyzed during the current study

Open Access. This article is licensed under a Creative Commons Attribution-NonCommercial 4.0 International License, which permits any non-commercial use, sharing, adaptation, distribution and reproduction in any medium or format, as long as you give appropriate credit to the original author(s) and the source, provide a link to the Creative Commons licence, and indicate if changes were made. The images or other third party material in this article are included in the article's Creative Commons licence, unless indicated otherwise in a credit line to the material. If material is not included in the article's Creative Commons licence and your intended use is not permitted by statutory regulation or exceeds the permitted use, you will need to obtain permission directly from the copyright holder. To view a copy of this licence, visit http://creativecommons.org/licenses/by$\mathrm{nc} / 4.0 /$.

\section{REFERENCES}

1. IHS. The International Classification of Headache Disorders, 3rd edition (beta version). Cephalalgia. 2013;33:629-808. https://doi.org/10.1177/ 0333102413485658 .

2. American Academy of Sleep Medicine. International classification of sleep disorders. 3rd ed. Darien: American Academy of Sleep Medicine; 2014. 
3. Koreshkina MI. Relationships of sleep disorders and headache. Zh Nevrol Psikhiatr Im S S Korsakova Spl Edn. 2018;35:72-9.

4. Romberg M. A manual of the nervous diseases of man. London: Sydenham Society; 1853.

5. Liveing E. On megrim, sick-headache and some allied disorders: a contribution to the pathology of nerve-storms. London: Churchill; 1873.

6. Freud S. The interpretation of dreams. Birmingham: The Classics of Medicine Library; 1988. p. 189.

7. Bing R. Lehrbuch der Nervenkrankheiten. Basel: Benno Schwabe; 1947.

8. Gans M. Treating migraine by "sleep-rationing". J Nerv Ment Dis. 1951;113(5):405-29.

9. Dexter JD, Weitzman ED. The relationship of nocturnal headaches to sleep stage patterns. Neurology. 1970;20:513-8.

10. Sahota PK, Dexter JD. Sleep and headache syndromes: a clinical review. Headache. 1990;30:80-4.

11. Goyal M, Singh N, Sahota P. Headache syndromes and sleep. In: Chokroverty S, Billiard M, editors. Sleep medicine. New York: Springer; 2005.

12. Lund N, Westergaard ML, Barloese M, Glumer C, Jensen RH. Epidemiology of concurrent headache and sleep problems in Denmark. Cephalalgia. 2014;34(10):833-45.

13. Kohlschütter E. Messungen der Festigkeit des Schlafes. Z Ration Med. 1863;17:209-53.

14. Kukushkin ML, Poluektov MG. Contemporary approaches to the relationships between chronic pain and sleep. Zh Nevrol Psikhiatr Im S S Korsakova. 2017;2(4):19-27.

15. Steriade M, McCormick DA, Sejnowski TJ. Thalamocortical oscillations in the sleeping and aroused brain. Science. 1993;262(5134):679-85.

16. Peever JH, Sessle BJ. Sensory and motor processing during sleep and wakefulness. In: Kryger $\mathrm{MH}$, Roth T, Dement WC, editors. Principles and practice of sleep medicine. 6th ed. Elsevier: Philadelphia; 2016. p. 239-249.

17. Ødegård SS, Omland PM, Nilsen KB, Stjern M, Gravdahl GB, Sand T. The effect of sleep restriction on laser evoked potentials, thermal sensory and pain thresholds and suprathreshold pain in healthy subjects. Clin Neurophysiol. 2015;126(10):1979-88. https://doi.org/10.1016/j.clinph.2014.12.011.
18. Roehrs TA, Harris E, Randall S, Roth T. Pain sensitivity and recovery from mild chronic sleep loss. Sleep. 2012;35(12):1667-722. https://doi.org/10. 5665/sleep.2240.

19. Cooperman NR, Mullin FJ, Kleitman N. Studies on the physiology of sleep. XI. Further observations on the effects of prolonged sleeplessness. Am J Physiol. 1934;107:589-93.

20. O'Hare M, Cowan RP. Sleep and headache. In: Miglis MG, editor. Sleep and neurologic disease. Amsterdam: Elsevier; 2017.https://doi.org/10.1016/ B978-0-12-804074-4.00011-X

21. Holland PR. Headache and sleep: shared pathophysiological mechanisms. Cephalalgia. 2014;34(10):725-44.

22. Gotter AL, Roecker AJ, Hargreaves R, Coleman PJ, Winrow CJ, Renger JJ. Orexin receptors as therapeutic drug targets. Prog Brain Res. 2012;198: $163-88$.

23. Holland PR, Goadsby PJ. The hypothalamic orexinergic system: pain and primary headaches. Headache. 2007;47(6):951-62.

24. Robert C, Bourgeais L, Arreto CD, et al. Paraventricular hypothalamic regulation of trigeminovascular mechanisms involved in headaches. J Neurosci. 2013;33(20):8827-40.

25. Holle D, Naegel S, Obermann M. Pathophysiology of hypnic headache. Cephalalgia. 2014;34(10): 806-12. https://doi.org/10.1177/ 0333102414535996.

26. Brennan KC, Charles A. Sleep and headache. Semin Neurol. 2009;29(4):406-18.

27. Brown RE, Basheer R, McKenna JT, Strecker RE, McCarley RW. Control of sleep and wakefulness. Physiol Rev. 2012;92(3):1087-187.

28. Dodick DW, Eross EJ, Parish JM, Silber M. Clinical, anatomical, and physiologic relationship between sleep and headache. Headache. 2003;43(3):282-92.

29. Evers S, DMKG Study Group. Migraine and idiopathic narcolepsy: a case-control study. Cephalalgia. 2003;23(8):786-9.

30. Rainero I, Gallone S, Valfrè W, et al. A polymorphism of the hypocretin receptor 2 gene is associated with cluster headache. Neurology. 2005;63: 1286-8.

31. Peres M. Melatonin, the pineal gland and their implications for headache disorders. Cephalalgia. 2005;25(6):403-11. 
32. Peres MF, Rio MS, Seabra ML, et al. Hypothalamic involvement in chronic migraine. J Neurol Neurosurg Psychiatry. 2001;71(6):747-51.

33. Williams GS. What's the relationship between sleep and headache? Neurol Rev. 2010;18(4):7.

34. Landolt HP. Sleep homeostasis: a role for adenosine in humans? Biochem Pharmacol. 2008;75(11): 2070-9.

35. Guieu R, Devaux C, Henry H, et al. Adenosine and migraine. Can J Neurol Sci. 1998;25(1):55-8.

36. Wang QP, Nakai Y. The dorsal raphe: an important nucleus in pain modulation. Brain Res Bull. 1994;34(6):575-85.

37. Ferrari MD, Saxena PR. On serotonin and migraine: a clinical and pharmacological review. Cephalalgia. 1993;13(3):151-65.

38. Silberstein SD. Serotonin (5-HT) and migraine. Headache. 1994;34(7):408-17.

39. Engstrom M, Hagen $\mathrm{K}$, Bjork $\mathrm{MH}$, et al. Sleep quality, arousal and pain thresholds in migraineurs: a blinded controlled polysomnographic study. J Headache Pain. 2013;14:12.

40. Ong JC, Park M. Chronic headaches and insomnia: working toward a biobehavioral model. Cephalalgia. 2012;32(14):1059-70.

41. Smith MT, Haythornthwaite JA. How do sleep disturbance and chronic pain inter-relate? Insights from the longitudinal and cognitive-behavioral clinical trials literature. Sleep Med Rev. 2004;8(2): 119-32.

42. Spielman AJ, Caruso LS, Glovinsky PB. A behavioral perspective on insomnia treatment. Psychiatr Clin N Am. 1987;10(4):541-53.

43. Buenaver LF, Quartana PJ, Grace EG, et al. Evidence for indirect effects of pain catastrophizing on clinical pain among myofascial temporomandibular disorder participants: the mediating role of sleep disturbance. Pain. 2012;153(6):1159-66. https:// doi.org/10.1016/j.pain.2012.01.023.

44. Smith MT, Perlis M, Smith MS, Giles DE, Carmody TP. Sleep quality and presleep arousal in chronic pain. J Behav Med. 2000;23:1-13.

45. Finan PH, Goodin BR, Smith MT. The association of sleep and pain: an update and a path forward. Pain. 2013;14(12):1539-52. https://doi.org/10.1016/j. jpain.2013.08.007.

46. Kelman L, Rains JC. Headache and sleep: examination of sleep patterns and complaints in a large clinical sample of migraineurs. Headache. 2005;45(7):904-10.

47. Guidetti V, Dosi C, Bruni O. The relationship between sleep and headache in children: implications for treatment. Cephalalgia. 2014;34(10): 767-76.

48. Graff-Radford SB, Newman A. Obstructive sleep apnea and cluster headache. Headache. 2004;44(6): 607-10.

49. Chervin RD, Zallek SN, Lin X, Hall JM, Sharma N, Hedger KM. Sleep disordered breathing in patients with cluster headache. Neurology. 2000;54(12): 2302-6.

50. Odegard SS, Engstrom M, Sand T, Stovner LJ, Zwart JA, Hagen K. Associations between sleep disturbance and primary headaches: the third NordTrondelag Health Study. J Headache Pain. 2010;11(13):197-206.

51. Spierings EL, Ranke AH, Honkoop PC. Precipitating and aggravating factors of migraine versus tensiontype headache. Headache. 2001;41(6):554-8.

52. Cho SJ, Chu MK. Risk factors of chronic daily headache or chronic migraine. Curr Pain Headache Rep. 2015;19(1):465.

53. Mitsikostas DD, Vikelis M, Viskos A. Refractory chronic headache associated with obstructive sleep apnoea syndrome. Cephalalgia. 2008;28(2):139-43.

54. Scher AI, Lipton RB, Stewart WF. Habitual snoring as a risk factor for chronic daily headache. Neurology. 2003;60(8):1366-8.

55. Yeung WF, Chung KF, Wong CY. Relationship between insomnia and headache in communitybased middle-aged Hong Kong Chinese women. J Headache Pain. 2010;11(3):187-95.

56. Langemark M, Olesen J, Poulsen DL, Bech P. Clinical characterization of patients with chronic tension headache. Headache. 1988;28(9):590-6.

57. Tardov MV, Poluektov MG. Sleep disturbance in chronic pain syndromes. Zh Nevrol Psikhiatr Im S S Korsakova. 2018;4(2):107-12.

58. Stepanski EJ, Walker MS, Schwartzberg LS, Blakely LJ, Ong JC, Houts AC. The relation of trouble sleeping, depressed mood, pain, and fatigue in patients with cancer. J Clin Sleep Med. 2009;5(2): 132-6.

59. Foo H, Mason P. Brainstem modulation of pain during sleep and waking. Sleep Med Rev. 2003;7(2): 145-54. 
60. Drewes AM, Nielsen KD, Arendt-Nielsen L, BirketSmith L, Hansen LM. The effect of cutaneous and deep pain on the electroencephalogram during sleep - an experimental study. Sleep. 1997;20(8): 632-40.

61. Evers S. Special issue on headache and sleep. Cephalalgia. 2014;34(10):723-4.

62. Dexter JD. The relationship between stage III + IV + REM sleep and arousals with migraine. Headache. 1979;19(7):364-9.

63. Kayed K, Sjaastad O. Nocturnal and early morning headache. Ann Clin Res. 1985;17:243-6.

64. Singh NN, Sahota P. Sleep-related headache and its management. Curr Treat Opt Neurol. 2013;15(6): 704-22. https://doi.org/10.1007/s11940-013-02581.

65. Podoll K, Topper R, Robinson D, Sass H. Recurrent dreams as migraine aura symptoms. Fortschr Neurol Psychiatr. 2000;68:145-9.

66. Nagtegaal JE, Smits MG, Swart AC. Melatonin responsive headache in delayed sleep phase syndrome: preliminary observations. Headache. 1998;38(4):303-7.

67. Peres MF, Zukerman E, da Cunha TF, Moreira FR, Cipolla-Neto J. Melatonin, $3 \mathrm{mg}$, is effective for migraine prevention. Neurology. 2004;63:757-61.

68. Bougea A, Spantideas N, Lyras V, Avramidis T, Thomaidis T. Melatonin $4 \mathrm{mg}$ as prophylactic therapy for primary headaches: a pilot study. Funct Neurol. 2016;31(1):33-7.

69. Deboer T, van Diepen HC, Ferrari MD, Van den Maagdenberg AM, Meijer JH. Reduced sleep and low adenosinergic sensitivity in cacna1a R192Q mutant mice. Sleep. 2013;36(1):127-36.
70. Makarov SA, Churukanov MV, Churukanov VV. Antidepressants in the treatment of pain. Rus J Pain. 2016;3-4(51):74-84.

71. Danilov AB, Davidov JS. Neuropathic pain. Moscow: Borges; 2007. p. 192.

72. Wilson S, Angyropoulos S. Antidepressants and sleep: a qualitative review of the literature. Drugs. 2005;65:927-47.

73. Flavell Matts SG, Hazelman BL, Houben H, Dhondt E, Tebbs VM. Controlled study of once-daily, sustained-release ibuprofen in osteoarthritis. Curr Ther Res. 1993;53:394-400.

74. Baumgartner H, Schwartz HA, Bloom V, et al. Ibuprofen and diclofenac sodium in the treatment of osteoarthritis: a comparative trial of two oncedaily sustained-release NSAID formulations. Curr Med Res Opin. 1996;13:435-44.

75. Calhoun AH, Ford S. Behavioral sleep modification may revert transformed migraine to episodic migraine. Headache. 2007;47(8):1178-83.

76. Eidlitz-Markus T, Haimi-Cohen Y, Steier D, Zeharia A. Effectiveness of nonpharmacologic treatment for migraine in young children. Headache. 2010;50(2): 219-23.

77. Stepanski EJ, Wyatt JK. Use of sleep hygiene in the treatment of insomnia. Sleep Med Rev. 2003;7(3): 215-25. https://doi.org/10.1111/j.1526-4610.2009. 01534 .

78. Korabelnikova EA. Psychotherapy of insomnia: the role of somnologist and psychotherapist. Zh Nevrol Psikhiatr Im S S Korsakova Spl Edn. 2014;12(38-44): 11. 